\title{
LA RECONSTRUCCIÓN SIGNIFICATIVA DE LA IGLESIA DE SANT BARTOMEU DE NAVARCLES, CATALUÑA-ESPAÑA
}

\author{
(THE MEANINGFUL RECUPERATION OF THE CHURCH OF SANT BARTOMEU DE \\ NAVARCLES, CATALUÑA-SPAIN)
}

Antoni González Moreno-Navarro, arquitecto.

Jefe del Servicio del Patrimonio Arquitectónico de la Diputación de Barcelona.

\section{RESUMEN}

En un arrabal de Navarcles (comarca del Bages, provincia de Barcelona), los restos de una pequeña iglesia medieval profanada en 1936 y abandonada a su suerte después de la guerra civil, corrian el peligro de desaparecer. Hacia 1984, el Ayuntamiento solicitó ayuda a la Diputación para detener el deterioro y dar alguna solución para la conservación de los restos.

Los trabajos cientificos iniciales evidenciaron que en la construcción de la capilla se habian aprovechado estructuras de una villa romana del siglo I y que el primer edificio del siglo XIII fue ampliado en el XVII, aprovechando algunos elementos de la portada románica primitiva.

La solución proyectada se basó en la consolidación de la ruina, y la habilitación de un pequeño espacio cubierto - que recuerda el volumen del templo inicial-delimitado por los muros medievales conservados y otros nuevos. Una plataforma separa este espacio de los restos romanos aparentes. La actuación se completó con una pequeña placita frente a la desaparecida fachada de tramontana.

\section{SUMMARY}

In the outskirts of Narvacles (county of Bages, province of Barcelona), the remains of a small medieval church. desecrated in 1936 and abandoned to its fortune after the civil war, ran the risk of disappearing. In 1984, the municipal government asked the Diputacio for help to stop the deterioration and offer some solution for the preservation of the remains.

The initial scientific work discovered that structures from a Roman villa from the I century had been used in the construction of the chapel, an that the first building from the XIII century was expanded in the XVII, taking advantage of some of the elements of the primitive Romanesque portal.

The solution projected was based on the consolidation of the ruin, and the construction of a small covered space - that recall the volume of the first temple-delimited by the preserved medieval walls and other new ones. A platform separates this from the Roman remains. The effort was topped off with a small square in fron of the now disappeared north façade.
Navarcles es un pequeño municipio de la provincia de Barcelona que ocupa el extremo oriental del llano de la comarca del Bages, a la izquierda del rio Llobregat y en el centro geográfico de Cataluña. El pueblo, del mismo nombre que el municipio, tiene entre tres y cuatro mil habitantes, y según cuentan enciclopedias y guias, aparte de la iglesia parroquial y de un bello puen. te moderno que todo el mundo da por más antiguo, sólo tiene otro monumento destacable: el templo dedicado al apóstol Bartolomé, la pequeña iglesia de Sant Bartomeu, en el arrabal de su nombre.

En realidad ni siquiera es un monumento entero. A nuestros días sólo llegaron los restos de la iglesita, que como un patético derrelicto arquitectónico embarran. cado entre el caserío destartalado, emergían de él singularizando una trama anodina.

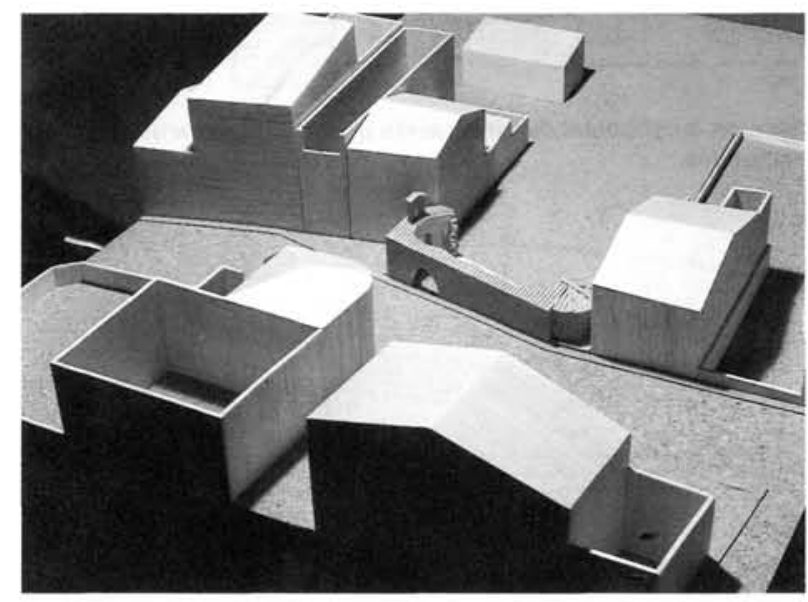

Situación de los restos de Sant Bartomeu en la trama urbana de $\mathrm{Na}$ varcles (Maqueta, Anna Álvaro; foto Joan Francés).

http://informesdelaconstruccion.revistas.csic.es 


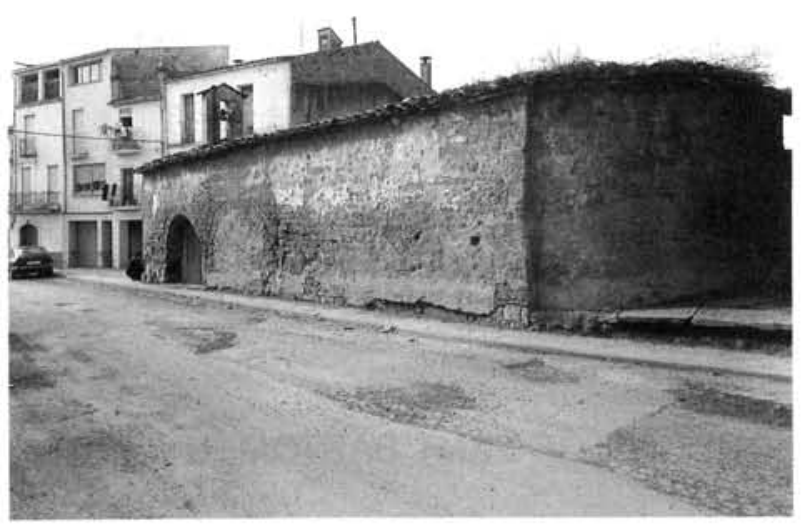

Los restos de la iglesia antes de la restauración. Fachada de medio. dia (Foto Joan Francés, febrero de 1985).

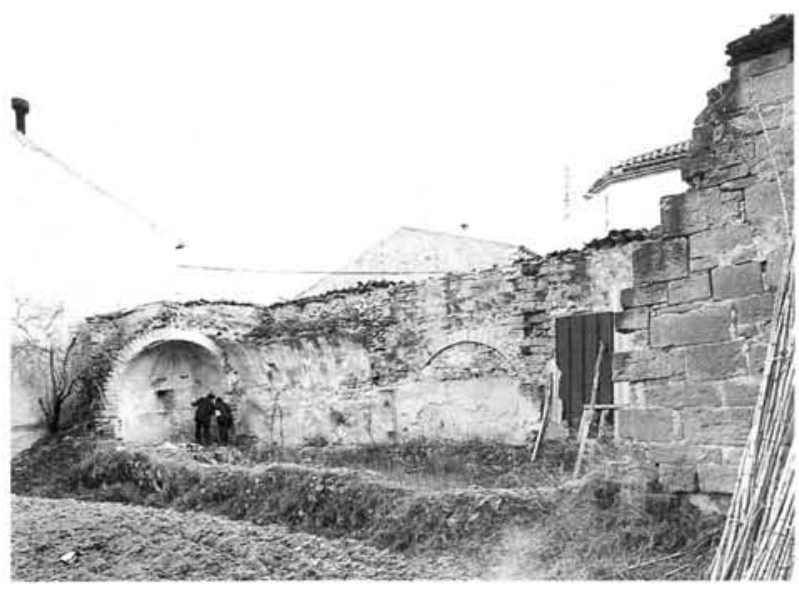

Interior arruinado: han desaparecido la cubierta y la fachada de tramontana (Foto Joan Francés, febrero 1985).

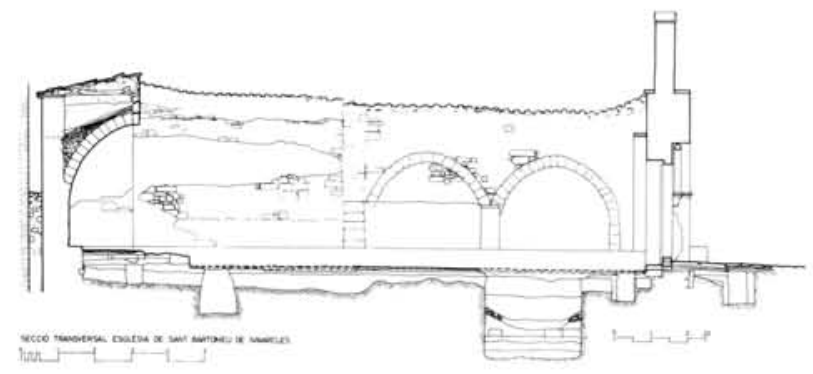

Sección longitudinal con indicación de los estratos arqueológicos excavados.

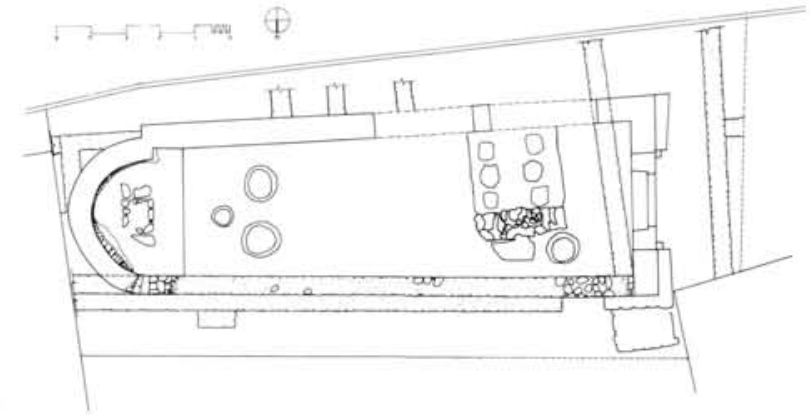

Planta con indicación de los muro romanos hallados en la excava. ción arqueológica.
Antes de la última guerra civil, el templo testimoniaba su antigüedad y su agitada historia en la maltrecha portada románica, en sus revocos con churretes y en su asimétrica espadaña. En 1936 la iglesia fue profanada y saqueada, y después de la guerra, abandonada. Con el tiempo perdió la cubierta y el muro de tramontana, cuyos restos fueron reutilizados en otras construccio. nes, quedando sólo en pie el ábside y los muros de mediodia y de poniente, éste con la portada. Hacia 1984, el Ayuntamiento, heredero moral de la titularidad de los despojos, solicitó ayuda a la Diputación para buscar una solución que evitara el que parecia un inminente final.

Antes de diseñar la actuación arquitectónica, que intentara hacer revivir la fábrica maltrecha, el Servicio del Patrimonio Arquitectónico de la Diputación, siguiendo su método de trabajo habitual, procedió a los exhaustivos trabajos científicos previos. Estos estudios descubrieron, en primer lugar, que en la construcción de la capilla románica tardia, iniciada en el siglo XIII, se habian aprovechado viejas estructuras de una conocida, pero no localizada hasta entonces, villa romana del siglo I de nuestra Era que estuvo en uso hasta el siglo IV.

Los trabajos arqueológicos también despejaron algunas incógnitas de la evolución posterior del edificio: el estrambótico templo, de nave desproporcionadamente alargada, habia tenido una planta inicial más adecuada. Poco después se construyó ante él un porche de tres arcos que fue emparedado en el siglo XVII para am. pliar la nave, momento en que algunos elementos de la portada románica primitiva fueron aprovechados para componer el nuevo acceso a los pies de la alargada iglesia resultante (').

Cuando se planteó el proyecto arquitectónico (2) se optó desde un principio por renunciar a cualquier intento de reconstrucción de la fábrica perdida. No sóto hubiera sido injustificada y temeraria por el hecho de conservarse únicamente la mitad, sino porque la complejidad y el valor testimonial de los restos conservados y superpuestos (muros romanos, muros del S. XIII y del S. XVII, etc.) aconsejaba buscar una solución que permitiera la conservación y la contemplación de todos ellos.

Sin embargo, tampoco se optó por hacer de las ruinas un simple testimonio, sin mayor contenido que el de emocionar o conmover. Se pensó que la mejor manera de potenciar el valor emblemático y significativo que podia tener el monumento (un medio fundamental para recalificar una trama urbana tan degradada como aquélla) era aprovechar los restos para configurar nuevos espacios de uso colectivo y enriquecer el conjunto con elementos cuyo uso o relativo valor material pudieran hacer estimar de nuevo los restos por parte de los vecinos. 
Estos objetivos indujeron a plantear una intervención rotunda conceptualmente: congelar la ruina que heredamos y, junto a ella, construir con materiales habituales los elementos necesarios para conseguir la "resignificación" social de aquel derrelicto. No se pretendia, pues, la reconstrucción física del monumento perdido, aunque sí, la "reconstrucción significativa", la recuperación de los significados emotivos, emblemáticos, que el lugar tenia para la colectividad. Todo ello se tradujo básicamente en la consolidación de la fábrica antigua, la introducción de una plataforma que protegiese los restos romanos y que permitiera el uso del espacio superior y el paso hacia la placita de tramontana, y la construcción de un edificio nuevo con materiales y diseño contemporáneos que aprovechara los muros existentes.
El nuevo edificio no reproduce exactamente la planta inicial del templo del siglo XIII, ya que la excavación, por desgracia, no pudo precisar exactamente la situación del muro perdido, es decir, el muro transversal de poniente que contenía la primitiva portada. De ahi que el nuevo cerramiento ligero siga una línea inclinada res. pecto al eje longitudinal, gesto que generó luego otros grafismos, como el del pavimento. También se aprovechó esa inclinación para lograr que el nuevo espacio cerrado se asomara al exterior por detrás de uno de los arcos del antiguo pórtico. De esta manera ese espacio podría recoger, a través del alabastro - la "pedra de llum" (piedra de luz) de nuestros abuelos-, el sol fugaz del invierno que baña la fachada medieval.

Planta de la solución final realizada.
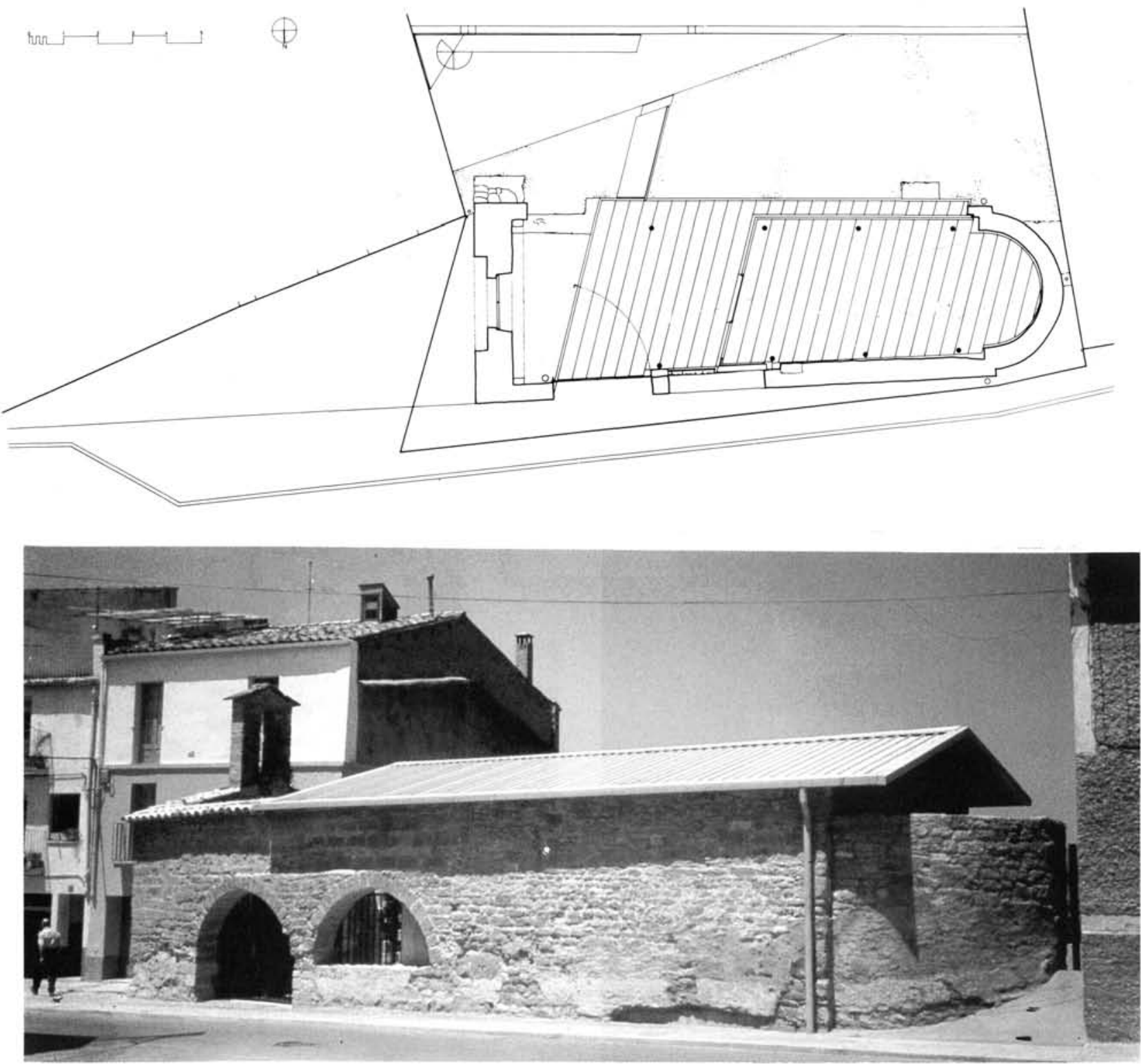

Vista de la fachada de mediodia después de la restauración (Foto Arxiu GMN, junio de 1990). 

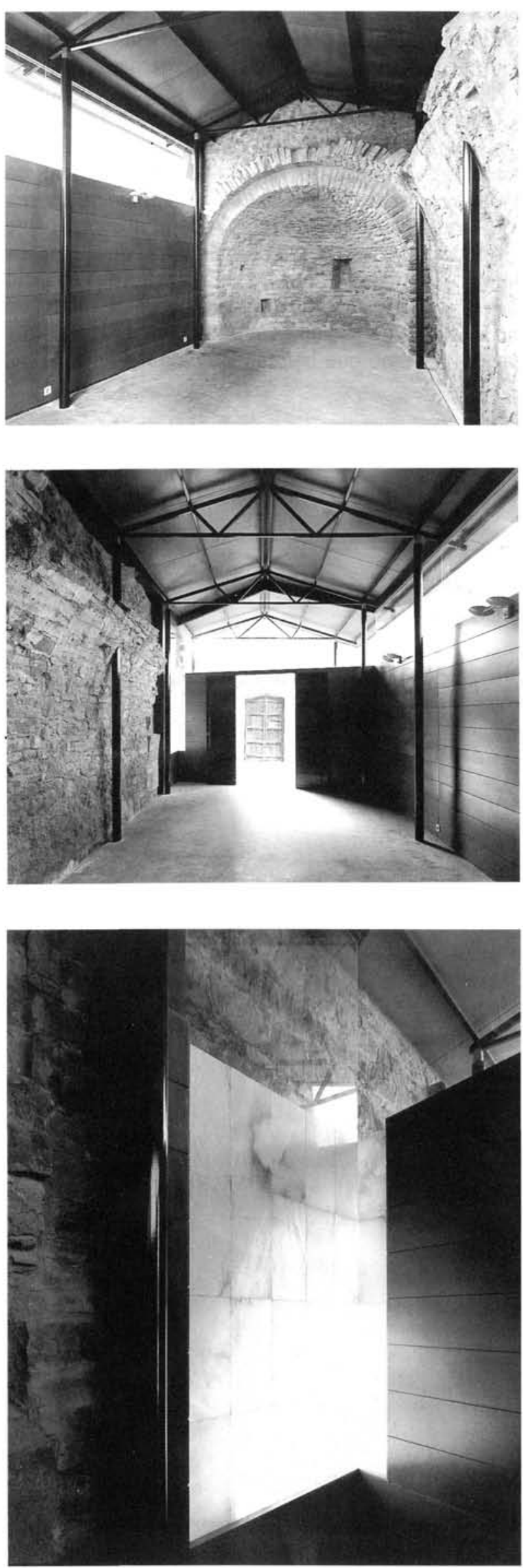

(C) Consejo Superior de Investigaciones Científicas Licencia Creative Commons 3.0 España (by-nc)
El otro arco del porche constituye hoy la entrada al recinto, ya que la portada medieval reutilizada en el siglo XVII, permanece cerrada por la puerta de madera que se ha conservado y fijado.

La cubierta del nuevo espacio cerrado es casi imperceptible desde el exterior de la antigua fábrica románica, para no alterar la imagen que de su iglesia tenían los navarcleses desde hace mucho tiempo. Por su parte, la estructura de ese nuevo espacio mantiene un diálogo respetuoso con las fábricas preexistentes, sin escatimar gestos de buena voluntad, como el de esas columnas que ceden el paso a los restos conservados de la bóveda original, convertidas en símbolo bien expresivo de la actitud que informa el proyecto.

En cuanto al pórtico, no sólo pretendia recordar el que hubo, sino que se trata de una zona libre ya que, según el planeamiento vigente, algún día aquél será un paso obligado a las instalaciones que deben ocupar unos terrenos vecinos a los que se accederá a través de la placita de tramontana. De momento, se ha creado en este rincón "un lugar en el sol" para los ancianos del lugar, un banco-escultura de hormigón visto encarado al sol y protegido del viento, al que se accede a través de la plataforma metálica que salva el foso que permite dejar vistos los restos romanos.

\section{Trabajos y materiales}

Una vez acabada la excavación arqueológica se procedió a realizar la cimentación de los nuevos elementos, protegiendo con láminas de poliuretano expandido los restos romanos. La cimentación se realizó con pozos

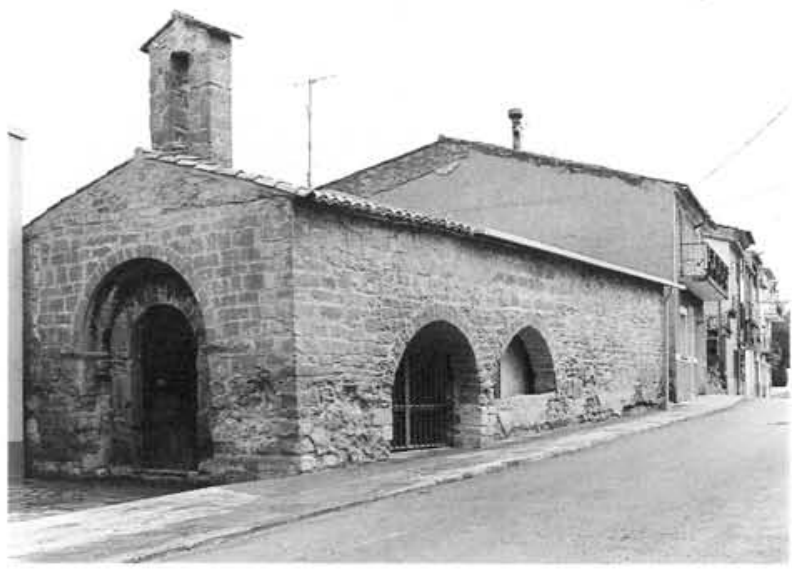

Dos aspectos del interior del recinto cubierto.

La ventana protegida con alabastro (Fotos Jorđi Isern, septiembre de 1989).

Exterior de los restos después de la restauración (Foto Jordi Isern. julio de 1990).

http://informesdelaconstruccion.revistas.csic.es 
y zanjas de hormigón armado y, al mismo tiempo, se recalzó el muro lateral de la fachada sur. Encima de esta cimentación se realizó un forjado sanitario con viguetas de hormigón, bovedillas cerámicas y chapa de compresión, formando un voladizo con acabado moldurado por encima de los restos del muro romano que habian servido de cimentación del muro románico hoy inexistente.

Por lo que se refiere al ábside, se saneó la cubierta, el arranque de la bóveda y toda la pared exterior. Después se consolidó la bóveda mediante encamisado, pintando con impermeabilizante el extradós.

La estructura del cerramiento nuevo se hizo a base de pilares y cerchas metálicas apoyadas aparentemente sobre dados de acero inoxidable. Sobre las cerchas se colocaron piezas de tablero conglomerado de madera del tipo "D.M." de 19 mm de grosor, especiales para exteriores y que, a la vez, sirven de acabado interior. Encima se colocaron unos paneles aislantes de $30 \mathrm{~mm}$ de grosor formados por una chapa de $0,5 \mathrm{~mm}$ de acero galvanizado, de espuma de poliuretano y acabado superficial a base de pintura de policloruro de vinilo de color beige.

El cerramiento vertical del nuevo espacio se confió a un material duradero, como es el ladrillo manual de $29 \times 14,50 \times 4,50 \mathrm{~cm}$. Este muro de 2,50 m de altura se remató con una pieza de mármol rosa de Portugal de $4 \mathrm{~cm}$, con tres caras pulidas y con un surco para recibir el cristal que sirve de cerramiento superior y permite la iluminación natural del local. La entrega de este cristal con la cubierta se hace con un marco de "D.M." de $19 \mathrm{~mm}$ de grosor.

El tipo de acabado de los cerramientos de este pequeño nuevo edificio se adecúan al uso previsto. Los muros antiguos conservan su textura, el interior del muro de obra vista se revocó y se aplacó con "D.M." barnizado mate y colocado sobre listones trabados con tacos para poner un paramento que permite ser usado como expositor. La luz penetra por las fachadas norte y oeste a través del friso de vidrio securizado superior $y$, por la de mediodia y poniente, por la citada abertura protegida con piezas de alabastro de $30 \times 45 \times 3 \mathrm{~cm}$ y vidrio de seguridad por la cara exterior.

El pavimento interior se hizo con piezas regulares de piedra de Sant Vicenç, de $60 \times 40 \times 2 \mathrm{~cm}$ acabada en diente de sierra. La puerta de acceso al aula es de madera de Bolondo, y está tratada formalmente de la misma manera que el tablero de "D.M." del paramento interior, a base de franjas horizontales.

En cuanto a los restos medievales se procedió en primer lugar a la limpieza, reposición de piedra y rejuntado de los paramentos de mampostería.

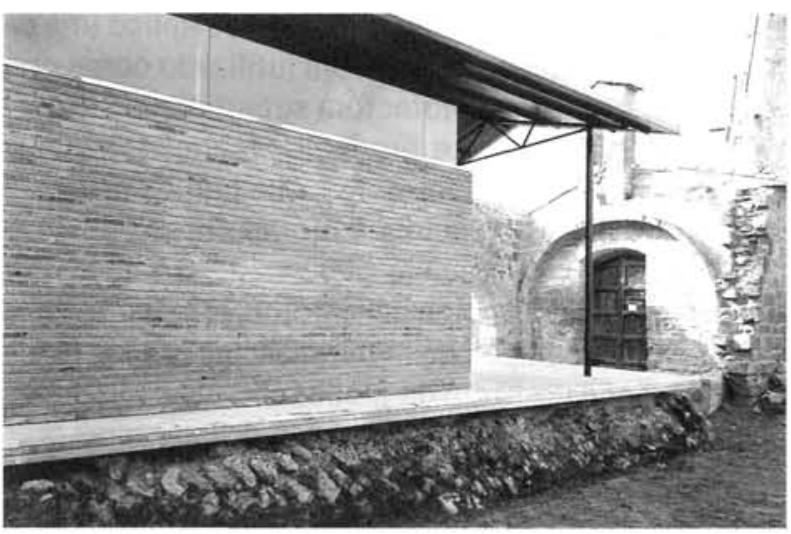

El muro romano, visible bajo la plataforma que lo protege (Foto Jordi Isern, septiembre de 1990).

El nuevo pórtico y la pasarela que salva el foso (Fotos Jordi Isern, julio de 1990).


http://informesdelaconstruccion.revistas.csic.es 
Finalmente, para su consolidación se aplicó una capa de penetración de Tegovacom (utilizado como consolidante) y una capa protectora superficial de Tegosivin HL-100, hidrofugante, productos fabricados con siliconas solubles en disolventes, que hemos de confesar que no dieron el rendimiento apetecido.

Respecto a la adecuación del entorno, el exterior se pavimentó con dos tipos de materiales: junto a las fachadas, hormigón de $10 \mathrm{~cm}$ de grosor con acabado de raspado manual, y siguiendo el trazado de las aceras pree- xistentes, baldosas de $20 \times 20 \mathrm{~cm}$ de cemento prensado. Los dos pavimentos están separados por una tira de mármol rosa de Portugal. La porción triangular accesible de la placita de tramontana también está pavimentada con hormigón continuo.

La iluminación de esta placita se realiza mediante una única lámpara. Fue elegida como homenaje a la arquitecta milanesa Franca Helg, fallecida en el mes de junio de 1989, que la habia diseñado en colaboración con los arquitectos Antonio Piva y Marco Albini.
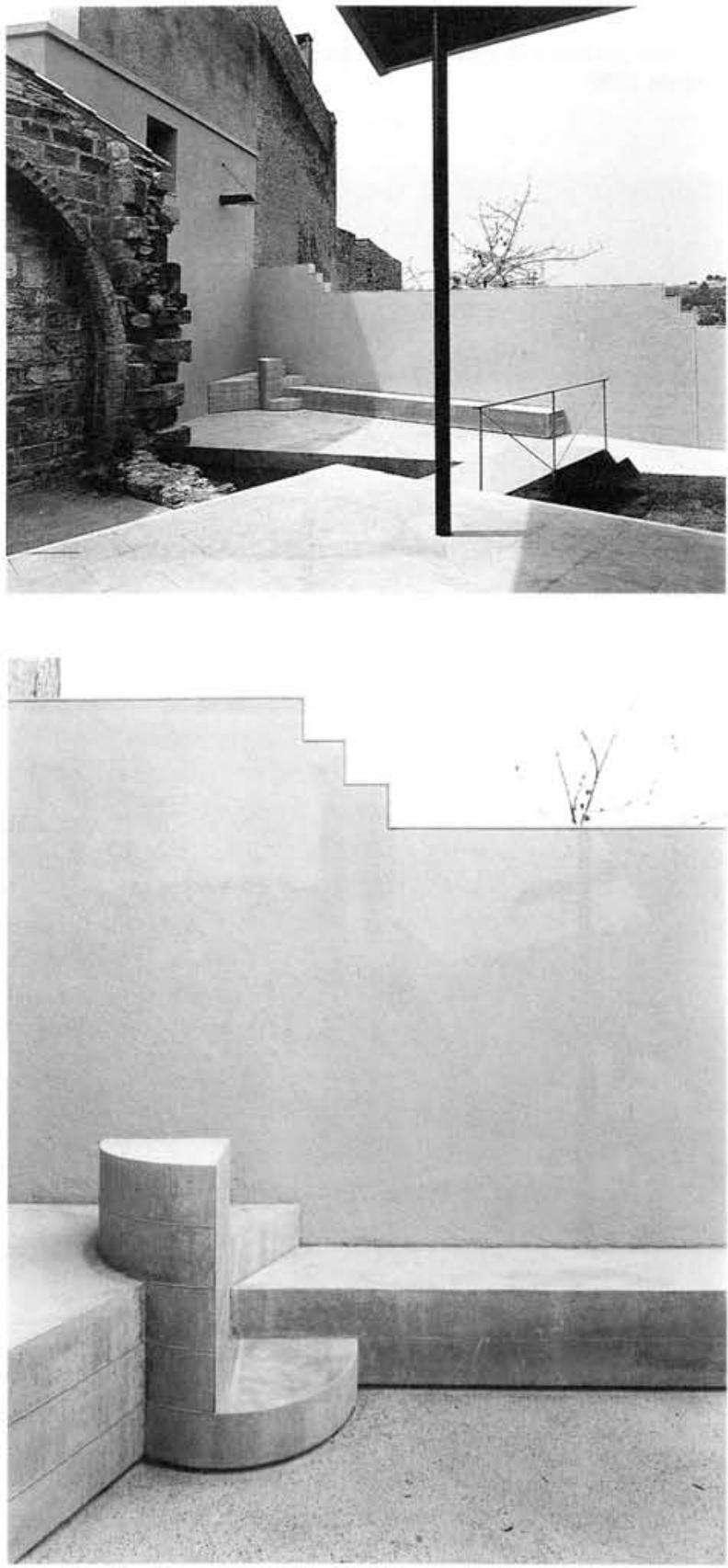

La placita de tramontana con el banco-escultura de hormigón (Fo. tos Jordi Isern, julio de 1990).

(C) Consejo Superior de Investigaciones Científicas Licencia Creative Commons 3.0 España (by-nc)
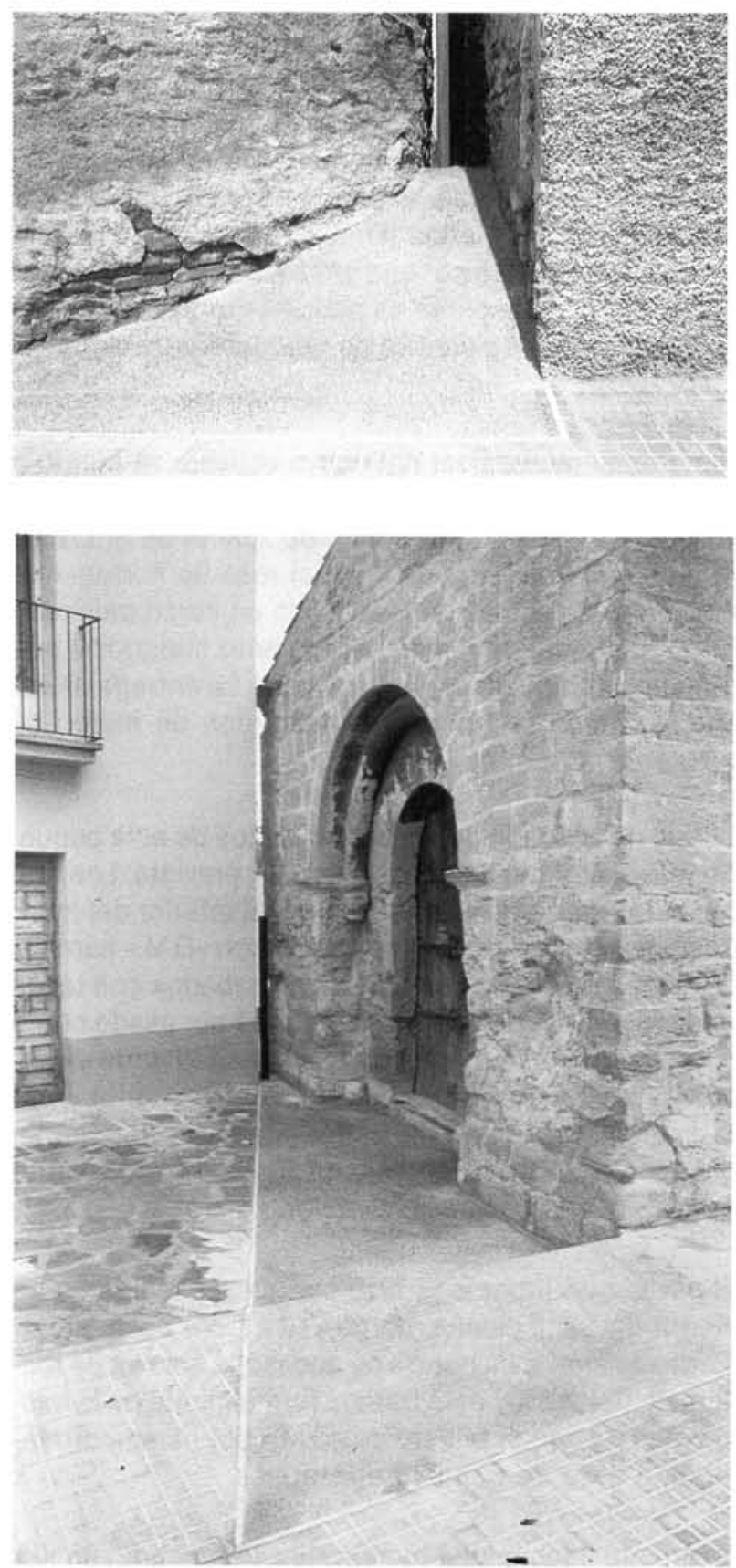

Detalles del pavimento exterior que rodea los restos restaurados (Fo tos Arxiu GMN, julio de 1990).

http://informesdelaconstruccion.revistas.csic.es 
NOTAS

(1) El equipo cientifico estuvo dirigido por el Dr. Alberto Ló. pez Mullor, jefe del departamento de Investigación del Servicio del Patrimonio Arquitectónico de la Diputación de Barcelona, que dirige Antoni González. Formaron parte los arqueólogos Xavier Solé, Alvar Caixal y Jordi Vallés, las historiadoras Anna Castellano (fuentes documentales), Ma. ria José Sureda (arte), Maria Clúa (numismática) y diversos especialistas en ceramologia, fauna y flora, y restos óseos humanos.
(2) El proyecto fue realizado por el arquitecto Antoni González Moreno-Navarro, que dirigió también las obras, ejecutadas entre febrero de 1986 y junio de 1990 , con un presupuesto algo inferior a 15 millones de pesetas, aportado in tegramente por la Diputación de Barcelona. En ambos trabajos colaboró la arquitecta Eulàlia Riera y en la dirección, la aparejadora Maria Ȧngels Bardolet y el aparejador Jo. sep Maria Moreno. Los constructores fueron Candi Prat, Josep Sabata y Xavier Vall. En los trabajos de gabinete colaboraron la maquetista Anna Álvaro, el fotógrafo Joan Francés y los delineantes Montserrat Cabo, Txetxu Sanz, Isabel Serra, Jordi Serra y Maite Gómez.

\section{publicación del IETcc / CSIC}

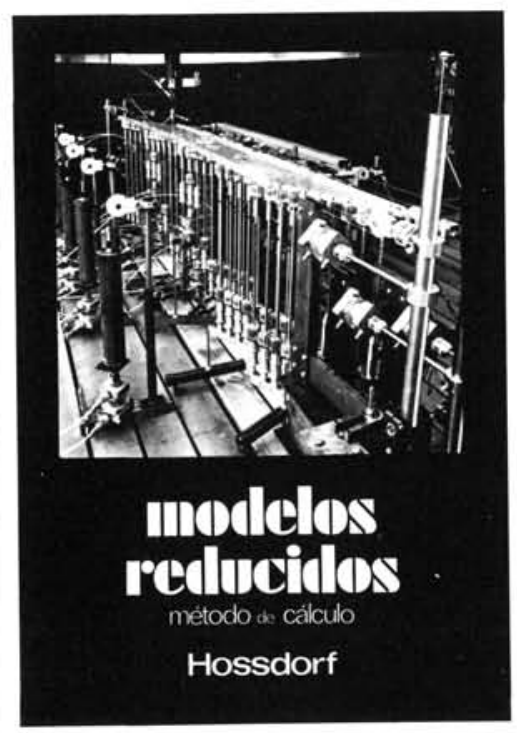

Modelos reducidos. Método de cálculo

H. Hossdorf, Ingeniero Civil

La técnica de los ensayos en modelos reducidos de estructuras sufre hoy dia una decisiva metamorfosis. Hasta hace poco era un medio más bien de artesa. Hasta hace pocompre era tomado en serio por los nia, que no siempre era tomado ender el comporta. académicos teorizantes Dara comprender el comporta. que se acudió las más de las veces, como a un que se acudio las mas de las veces, como a un cias. Sin embargo, en poco tiempo y gracias a su cias. Sin embargo, en poco tiempo yracias a su conexión con los ordenadores digitales, se ha trans formado en un instrumento cientificamente valioso, diaria del Ingeniero Proyectista.

Un volumen encuadernado en cartoné plastificado Co $17 \times 24 \mathrm{~cm}$, compuesto de 250 páginas, 158 figuras y fotografias.

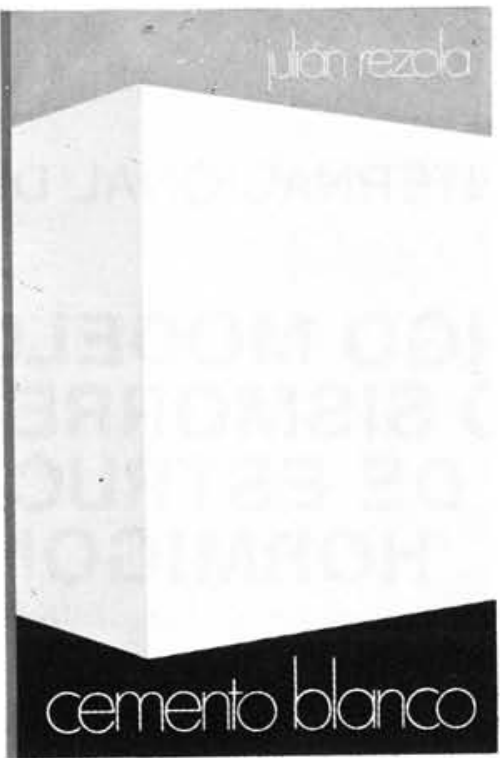

\section{Cemento blanco}

Julián Rezola

Ingeniero Quimico Dipl. I. Q. S.

Sabido es que existe una extensa y documentada bibliografia sobre el cemento gris: en cambio, no puede decirse to mismo acerca del cemento portiand blanco, ya que los escritos existentes se refieren tan sólo a algunas peculiaridades que le distinguen de aquél.

El autor nos ofrece sus profundos conocimientos y su larga experiencia tanto en laboratorio como en fabricación.

La parte descriptiva del libro se complementa cor gráficos, diagramas y fotografias de gran utilidad, grastinados a conseguit la aplicación apropiada de

Un volumen encuadernado en cartoné policerado, de $17,4 \times 24,3 \mathrm{~cm}$, compuesto de 395 páginas. numerosas figuras, tablas $y$ ábacos.

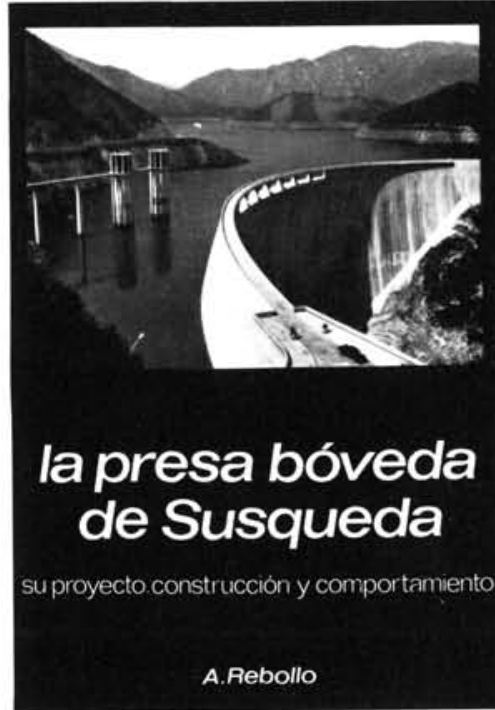

La presa bóveda de Susqueda

A. Rebollo,

Dr. Ingeniero de Caminos

El esfuerzo del constructor de presas se sitúa, por su pretension de perennidad, a contracorriente de las tendencias de la civilización actual, caracte. rizada por lo fungible. Pueden evocarse las 10.000 grandes presas en funcionamiento o en construcción que están envejeciendo y reclaman los cuidados gerontológicos para mantener y perfeccionar su servicio y garantizar su inalienable pretension de perennidad. En la medida en que todas nuevas obras, grandes o pequeñas, son portadoras de riesgos ecológicos $y$, a veces, catastroficos, que aumentan con el envejecimiento, la gerontologia de las presas es todo un emplazo. La accion adelantada de Arturo Rebollo en este terreno marca un camino a seguir para todos los que aman su propia obra con la devoción paternal que él ha puesto en Susqueda

Un volumen encuadernado en cärtoné plastificado con lomo de tela, de $18 \times 24.5 \mathrm{~cm}$, compuesto de 408 páginas, 330 figuras y fotografias y 39 tablas. 